\title{
Does Social Capital Matter in the Well-Being of Rural People?: A Study in the Central Province of Sri Lanka
}

\author{
K.W.H.A.N. Somaratne, O.G. Dayaratne ${ }^{1}$ and H.V.A. Wickramasuriya ${ }^{2 *}$ \\ Postgraduate Institute of Agriculture \\ University of Peradeniya \\ Peradeniya
}

\begin{abstract}
Social capital has widely been discussed among scholars and practitioners as an important resource in creating well-being. But research conducted on social capital in Sri Lankan societies has not been much and hence, it is an inadequately discussed concept locally. Therefore, the objective of this study was to examine the relevance of social capital in creating well-being in the selected local scenario of rural areas in the Central Province. A positive relationship was hypothesized between the two variables. The sample size was 420 individuals and multi stage stratified random sampling was adopted. Questionnaire was the data collection tool. The weighted principle component was used to develop indices for social capital and well-being. A bivariate correlation matrix and a simple regression Model were developed to examine the association. A significant and positive association was found, but the strength of the association was only moderate. Also, social capital explained only a small variation of well-being. Therefore, this research concluded that though social capital contributed significantly to well-being, it has not been able develop a strong association by itself; the other types of capital embedded in social relationship were also important. The prevailing rural characteristics of poverty and deficient diversity in social relationships were explained as major factors that weakened the strength of the association between social capital and well-being.
\end{abstract}

Key words: Social capital, well-being.

\section{INTRODUCTION}

\section{The context of the research and its objective}

This paper presents findings of a study conducted on the interrelationship between social capital and well-being of rural people in selected rural areas in the Central Province of Sri Lanka. It hypothesised a positively significant and strong relationship between the two variables. The need arose for this study because of the scarcity of research on social capital and its relevance to well-being in the Sri Lankan context.

There were a number of theoretical and empirical examinations explaining the relationship between social capital and well-being of people in different social contexts and almost all those studies found that social capital was of high importance for creating well-being. For example, a case studied in Gal-Oya in Sri Lanka by Uphoff and Wijeratne (2000) explained,

To whom correspondence should be addressed to: heshan54@gmail.com Department of Economics, Faculty of Arts, University of Peradeniya, Sri Lanka

Department of Agricultural Extension, Faculty of Agriculture, University of Peradeniya, Sri Lanka 
how the villagers successfully overcame water scarcity during severe drought at one cultivation season, through effective utilization of the social relationships. Among prominent studies conducted in other countries, the economic and educational success of immigrants in the Unites States and Britain was often discussed as a matter of social capital in well-being (Stirrat, 2003). Putnam (1993) explained that the difference of well-being (in terms of higher levels of output per capita and better governance) in North and South Italy was because of the higher endowment of social capital in Northern Italy compared to the Southern. The Productivity Commission of Melbourne (2003) reported that people with more social capital tend to be more "hired, housed, healthy and happy". Stone and Hughes (2001) showed that people often locate jobs through personal contacts (informal means) than formal job advertisements. This study also empirically found that the association between social capital and well-being was a significantly positive one. However, the strength of relationship was only moderate, and variation of well-being explained by social capital was small. Therefore, the major contention was that social capital alone cannot make a strong impact on one's well-being, and hence it was more of a complementary capital. Therefore, in contrary to the notion of social capital as a 'magic bullet' (Stirrit, 2003) of creating well-being, this study argues that social capital does a mere facilitating role to mobilise resources among actors in social relationships to create well-being.

\section{Conceptualization of the key concepts}

This section will explain how the concepts of social capital and well-being (the two key concepts) were defined and comprehended.

\section{Social capital}

Social capital is defined operationally as the total stock of social relationships that an individual possesses. Conceptually, this study viewed social relationships as the basic element of social capital, and categorized them into two major types (a) one's general social relationships and (b) special social relationships.

While someone making social relationships is an inevitable social phenomenon (Cox, 1997; Chitamber, 1973 and Carroll, 2000), she/he most commonly has social relationships with family and the network of kin, peers at the place of work, and school and so on. They are called general social relationships. One of the most prominent features of general social relationships is that they are being readily available or pre-designed for individuals. For example, when persons are born, the family relationships are already there for him/her; he/she does not have to make an effort to create family relationships, and instead the relationship to the mother, father, sisters and brothers, aunts, uncles, grandparents etc. are pre-designed and readymade. According to this study, the social entities that generate general social relationships are called 'inevitable social entities'. The reason is, because individuals do not have a choice to be or not to be in those relationships; inevitably he/she is a node of the network of those relationships. Another example is the place of work; whether a person prefers or not, she/he has to develop and maintain relationships with bosses, peers, and subordinates in the organization to survive in that social entity.

Out of these, one or several general social relationships can be grown in to very near and dear relationships, which are defined in this study as special social relationships. For example, of the family members, one sister can become a very close, trustworthy person, or among the schoolmates or workplace peers, one or two can become best friends. The special social relationships contain a lot more trust and certainty compared to general social 
relationships. The prime difference between general and special social relationships is that general relationships are usually more in number but shallow in depth of the bond, whereas special social relationships are few in number, but deeper in bonds. With this conceptualization, one's Total Stock of Social Capital (TSSC) was mathematically depicted as the sum of his/ her General Social Relationship (GSR) and Special Social Relationship $(\mathrm{SSR}): \mathrm{TSSC}=\mathrm{GSR}+\mathrm{SSR}$.

\section{Well-being}

According to Dasgupta (1993), well-being is said to be an ambiguous concept with many usages, meanings, and conceptions. It was defined in this study as the "perceived levels of satisfaction (by individuals) towards the economic and social standards that he/she enjoys". Therefore, operationally, it had two strands, (a) economic well-being and (b) social wellbeing.

Economic well-being was the perceived level of his/her satisfaction towards income and income security. Conversely, social well-being was the perceived level of satisfaction towards his/her dignity of self. One's Total Well-Being (TWB) was mathematically depicted as the sum of his/her Economic Well-Being (EWB) and Social Well-Being (SEB): (TWB = $\mathrm{EWB}+\mathrm{SWB})$

\section{METHODOLOGY}

\section{Operationalizing the key concepts}

The measurement of the two key concepts was a challenge as they are abstract in their nature. Proxy-indicators were used and the validity of those indicators was thoroughly tested through a pilot questionnaire, review of literature, and the reviews done by a panel of researchers. The duration of the field research conducted was approximately two years from 2006- 2008.

\section{Measuring social capital}

There were two separate sets of proxy-indicators developed to measure one's general and special social relationships. The general social relationships were captured with the proxyindicators of: (a) does the respondent feel that all his/her immediate family members are equally fond of him/her, (b) does the respondent feel that he/she is equally fond of all the immediate family members, (c) what percentage of neighbours does the respondent visit during the New Year festival, (d) what percentage of neighbours visit the respondent during the New Year festival, (e) does the respondent have membership to several organizations, (f)how frequently does the respondent participate in 'Shramadana' activities organised by the village?

The proxy-indicators developed for special social relationships were, (a) whether the respondent has at least one person to share a personal secret, (b) whether the respondent has at least one person to lend him/ her money unconditionally at an emergency, (c) whether the respondent is confident that at least there is one person in his/her life, who will not leave $\mathrm{him} / \mathrm{her}$ even at a desperate situation. 


\section{Measuring well-being}

The proxies for economic well-being were (a) whether the monthly income of the respondent is enough to cover the monthly expenses without being indebted and also to save some amount, (b) whether the respondent has alternative income sources to survive at an economic shock, (c) whether the respondent has savings to face an economic shock, and (d) whether the respondent has debt burdens.

Proxies developed for social well-being were (a) the perceived level of satisfaction of the respondent towards his/her life lived so far, (b) his/her overall satisfaction towards recognition given to him/her by the family, and (c) by the society that he/she lives.

A questionnaire was administered as the major tool of data collection. There were two indices constructed for social capital and well-being to interpret levels of social capital and well-being. The indices were prepared with the method of Weighted Principle Components, and hence allocated weights to each of the items (above proxy-indictors) according to the relative importance (weight) of those items for measuring the variable. Therefore, allocating equal weights to each item of the variable without considering their relative importance (weights), which was a common problem found in social capital measurements, was eliminated. This is one of the significant features of the indices developed.

\section{Sampling and data collection}

The sampling framework was Divisional Secretariat Divisions (DSDs) of the Central Province. The sample size was 420 rural people, selected with Multi-Stage Stratified Random Sampling. First, the rural DSDs were extracted by taking the national median of the rural population as the cut-off point determining the rural DSDs. Second, the selected rural DSDs were further divided into two categories as better-off and poor DSDs. As data on wellbeing were not available, income poverty (Head Count Index-HCI of 2002 data) was taken as a proxy indicator for well-being. Two categories of DSDs were formulated for sampling; (1) rural DSDs with better levels of well-being, and (2) rural DSDs with poor levels of wellbeing. In the third step, those DSDs were sorted out according to the districts and of them 14 DSDs, and from each DSD three villages were randomly selected. The number of families selected from each village was 10 and finally, one respondent from each family was taken randomly for the sample. However, the family members below the age of 18 were purposely excluded, because the questions in the questionnaire were more related to adults' experiences on social relationships and well-being.

\section{Data analysis}

The unit of analysis was individuals. The Statistical Package for Social Sciences (SPSS) was used to construct indices for social capital and well-being and also to examine the relationship between them. First, a scatter plot between the two variables alone with bivariate correlation matrix was done to find out the pattern of the relationship. Then, a Simple Linear Regression Model (as illustrated below) was developed to find out the extent of the wellbeing explained by social capital in that model. The set level of $\alpha$ was 0.05 .

$\mathrm{E}(\mathrm{TWBE} / \mathrm{SC})_{i}=\beta_{0}+\beta_{1} \mathrm{SC}_{i}+\mathrm{V}_{i}$ 
The abbreviations TWBE and SC in the following equations indicate the terms of Total Well-Being and Social Capital, respectively.

$\mathrm{E}(\mathrm{WBE} / \mathrm{SC})_{i}=$ Conditional expectation of Total Well-Being in given level of SC for $\mathrm{i}^{\text {th }}$ individual

$\beta_{0}=$ intercept of the model

$\beta_{1}=$ slope coefficient

$\mathrm{SC}=$ Social Capital of the $\mathrm{i}^{\text {th }}$ person

$\mathrm{V}_{i}=$ error term of the equation

\section{RESULTS AND DISCUSSION}

The scatter diagram drawn between the two variables indicated a positive relationship or a pattern of increasing well-being with increasing social capital. The correlation coefficient $(r)$ was 0.346 , which indicated a moderately strong relationship between the two variables.

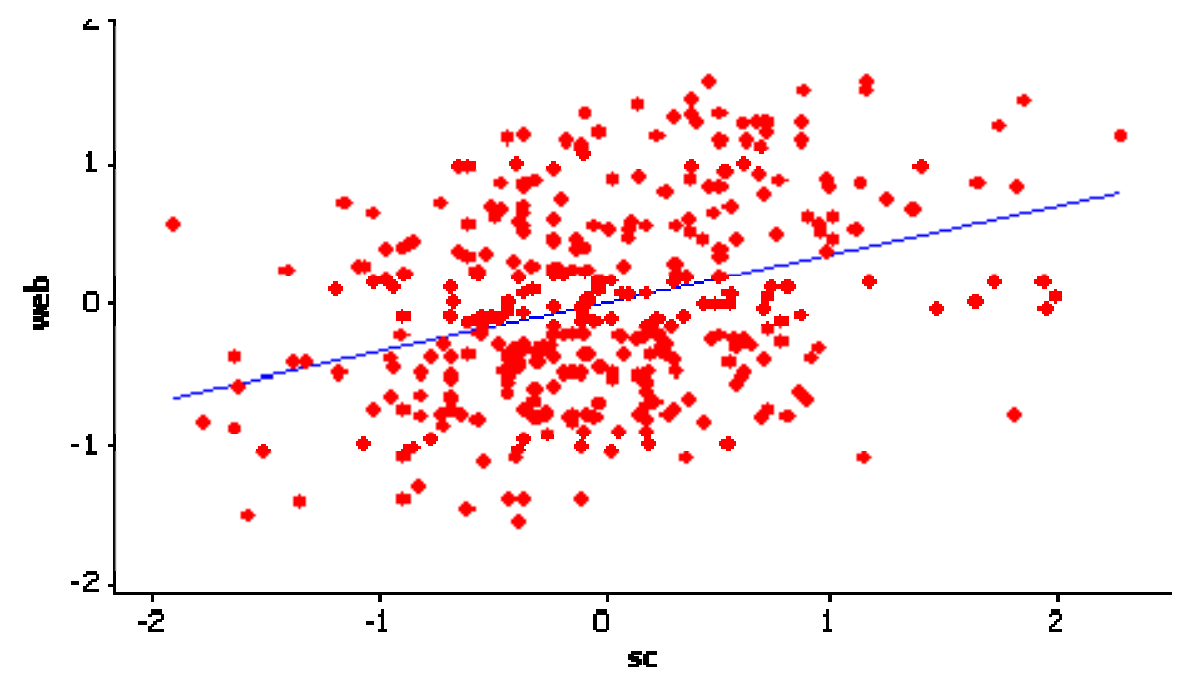

Fig. 1. The relationship between social capital (sc) and well-being (web)

The simple linear regression model reconfirmed the hypothesised relationship between the two variables with the obtained values of $\mathrm{p}=0.000$ and $\mathrm{t}=6.82$. The model resulted in was:

$(\mathrm{WEB} / \mathrm{SC})_{i}=0.0042+0.344 \mathrm{SC}_{i}$

$$
\text { (0.116) (0.000) }
$$

However, the above model was found to be explaining only $12 \%$ of the variation of wellbeing by social capital (the adjusted $\mathrm{r}^{2}=12 \%$ ). Therefore, it could be suggested that the wellbeing of people in the studied context was explained more by other variables than the social 
capital. The major contention developed in this study based on these results was, social capital alone cannot have a strong association with well-being, and the other resources embedded in social relationships (or resourcefulness) are of high importance. The moderately strong relationship between the two variables was explained as a matter of inadequate resource embedded in social relationships.

\section{Resourcefulness in social relationships}

The resourcefulness of a relationship comes in terms of physical, human, and moral resources. The physical resources are namely, money and other tangible assets possessed by the social actors in the relationships. Human resources consist mainly of education and health status of social actors. Moral resources are the human qualities such as kindness, being generous, empathic, and altruistic and so on. When social actors in a relationship have all three types of resources equally, they were assumed to be rich in social capital according to this study. Further, the deprivation of one type of above explained resources can reduce the total quality of a social relationship, so as the richness of social capital stock. For example, an individual can be rich in economic resources, well educated and healthy, but if she/he is stingy (poor in moral resources) the ability to contribute to well-being of other actors in the social relationships is less. On the contrary, if an individual is rich in economic assets, well educated and in good health, while being kind and generous she/he will largely contribute to the well-being of the others in his/her social relationship. According to the purview of this study in such instances, a stronger association between social capital and well-being can be seen.

However, the resourcefulness of social relationships was explained in this study as an aspect sensitive to several external socio-economic factors. The prevalence of poverty (in terms of economic and human poverty) and poor diversity in social relationships in the rural societies were described as the major factors that weakened resourcefulness in social relationships.

\section{Economic resource, social capital and well-being}

Persons in social relationships having economic resources is an important aspect affecting social capital; by confirming it this study found a significant and positive relationship between the individual's income and social capital levels $(\mathrm{p}=0.000, \quad r=0.222)$. Approximately, $77 \%$ of the studied sample was found to be living with an income below the poverty line, and hence it reconfirmed the fact that poverty is a rural phenomenon (Chitamber, 1973; Narayan and Pritchett, 1997 and World Bank, 2005). The economic indicators of household income, and percentage of population below the poverty line illustrated in Tables 1 and 2 are some basic evidence showing poverty being concentrated in the rural sector.

Table 1. Poor population (in thousands) in the rural and urban sectors

\begin{tabular}{lc}
\hline Sector & Poor population (in thousands) \\
\hline Urban & 184 \\
Rural & 2303 \\
\hline
\end{tabular}

Source: Department of Census and Statistics (2006/07) 
Table 2. Consumption poverty

\begin{tabular}{lc}
\hline Sector & Percentage head count \\
\hline National & 15.2 \\
Urban & 6.7 \\
Rural & 15.7 \\
\hline
\end{tabular}

Source: Department of Census and Statistics (2006/07)

While the rural population represented close to $85 \%$ of the country's total population, $90 \%$ of the poor people were in the rural sector (UNDP, 2005). The Central Province has $22.31 \%$ of poor households, which was significantly a higher figure compared to the Western Province $(8.2 \%)$, the most urbanized province of the country. Also, $82 \%$ of the population in the Central Province was rural (UNDP, 2005). Therefore, a majority of rural social relationships in the province can be assumed as relationships with poorly embedded economic resources thus, when a rural poor forms a social relationship with another rural poor, that relationship has only a little capacity to contribute to each other's well-being. For example, in instances such as one social actor facing an economic-shock or finding for capital to start a new business, the ability of contributing to this economic need by other actors is limited, even if they wish to support him/her wholeheartedly.

\section{Diversity in social relationships and well-being}

Cox (1999) and Carroll (2000) pointed out the importance of diversity of social relationships with regard to creating well-being. Diversity of social relationships brings more resources to people. For example, Granovetter (1973) empirically explained that in job seeking, an individual's distant relationships are more useful than close friendly and family members, because the latter has more or less similar contacts, whereas, more distant acquaintances have new and different contacts that can link up him or her to new and unexplored opportunities.

The rural areas are normally characterised with low social diversity. According to Chitamber (1973) rural society is a "small world", which does not have many opportunities to meet and interact with diverse social connections and networks. It is basically characterized with small in size, less density in population, and geographical isolation. As a result, they have fewer personal connections per individual. The community composition is homogeneous as the vast majority is in the same class, caste, occupation, religion, and ethnicity (Chitamber, 1973; Vathsayan, 1990 and Perera, 1997). Their geographical mobility was also slow, and of the sample of this study, around $41 \%$ said that they rarely go out of the village and almost every day they deal with the people in the same village. As they mentioned, village boutiques, village temple, relatives, native doctor, village school were the most common social entities that they dealt with. Approximately 59\% also said that they were born and grew up in the same village and hope to continue life there till their death. Therefore, this study argued that this limited geographical mobility has further hindered the development of diverse social networks with more embedded resources. In addition to geographical mobility, the career and social mobility were also found to be low. A significant proportion of the sample (34\%) was farmers and another $12.7 \%$ and $9.6 \%$ were in government and private sector jobs respectively. Among those jobs, assistant clerks, office peons, hospital helpers, and hotel/restaurant waiters, Jukey machine operators in garment factories were the most commonly found ones. Therefore, there was little opportunity available to develop diverse social relationships with richly embedded resources. 


\section{Rural social norms, social capital and well-being}

Rural people usually have strong communal feelings (Chitamber, 1973 and Vathsayan, 1990) and their social solidarity results mainly from common trait and similarity of experience than from the dissimilarity. With the communal affinity, they expect their community members to adhere to their traditions, norms, beliefs, and values, and tend to reject people who question and challenge the conformist norms. Therefore, the relationships formed in the rural are highly personal and informal (Chitamber, 1973 and Vathsayan, 1990). As observed in this study too, they were keen to distinguish between villagers who have origins to their villages as 'our ones' and who came from outside and live in the village as 'not our ones' or 'outsiders'. However, while rural people have more of intra-community ties than intercommunity ties (Carroll, 2000), those intra-community ties further split into intra-root (similar roots to the place of origin, such as Up-country and Low country born, and caste), which are stronger than intra-community relationships. Therefore, intra-community fragmentations were observed in some villages studied. More importantly, it was seen that the groups in those community fragments directly or indirectly try to exclude the "nonsimilar' people in instances such as appointing leaders in village organizations, especially in the temple society, and preventing young generation from marriages with families with nonsimilar social origins such as caste. These were some prominent instances observed on their dislike towards mixing with dissimilar people.

\section{CONCLUSIONS AND RECOMMENDATIONS}

Though social capital was found to be a significantly associated factor with well-being of the studied rural life, the strength of this association was low. Therefore, this study emphasizes the importance of resources (economic, human, and moral) embedded in social relationships to create a stronger association with well-being. The high prevalence of poverty and poor diversity in rural social relationships were explained as two key factors that reduced the resources embedded in relationships. Further, social capital was found to be a complementary capital, which harmonizes other types of resources for the betterment of actors in those relationships. Therefore, without other capital, social capital alone will not create a strong impact on well-being.

Based on the above findings, this study recommends that social capital should not be viewed as a 'magic bullet' (Stirrat, 2003) that creates well-being of rural people. The rural development programs planning to develop social capital need to consider the development of other resources as well.

\section{REFERENCES}

Carroll, T. (2001). Social capital, local capacity building and poverty reduction. Asian Development Bank, Manila.

Chithamber, J.B. (1973). Introduction to sociology. Wiley Eastern Pvt. Ltd. New Delhi, India.

Cox, E. (1997). What is social capital. [on line] [cited 20.05. 2007] < http://mapl.com.au $>$ 
Dekker, P. (2004). Social capital of individuals. In: Investigating social capital. Prakash S. and Selle P. (Eds.) New Delhi, India.

Dasgupta, P. (1993). An inquiry into well-being and deprivation. Clarendon, Oxford, UK.

Granovetter, M.S. (1973). The Strength of Weak Ties, Am. J. of Sociol. 78(6), 1360-1368.

UNDP, (2005). United Nations Development Program and National Council for Economic Development Program, Sri Lanka report of millennium development goals. [on line]. [cited 12.122.2007]. <http://www.mdg.lk>.

Perera, B.A. T. (1995). Gemi samajaya pilibanda handinveemak. In Samaja vimasuma. 9, 22-129.

Productivity Commission of Melbourne (2003). Social capital: reviewing the concept and its policy implications. Ausinfo. Canberra, Australia.

Putnam, R. (1993). Making democracy work. Princeton university press, Princeton.

Putnam, R. (2000). Bowling alone: The collapse and revival of American community. Touchstone, NewYork,NY.

Statistical abstracts of Sri Lanka (2008).[online]. [cited 3.08,2008].< http://www.staistics.gov.lk>.

Stone, W. and Hughes J. (2001). Social capital: empirical meaning and measurement validity. Australian institute of family studies, Melbourne.

Stirrat R.L. (2003). The concept of social capital. In Centre for Poverty Analysis, Improving Capacity for Poverty Research Program, University of Colombo, Sri Lanka Association for the Advancement of Science.

Uphoff N. and Wijayaratne C.M. (2000). Demonstrated benefits from social capital: The productivity of farmer organizations in Gal Oya, Sri Lanka. [on line].[cited 20.05.2006] $<$ ces.iisc.ernet.in>

Vatsayan (1991). Rural sociology. $6^{\text {th }}$ ed. Meerut: Kendra Nath Ram Nath.

World Bank. (2005). The poverty manual. Washington D.C. 